\title{
Does the age at adiposity rebound reflect a critical period?
}

Marie Françoise Rolland-Cachera ${ }^{1}$ and Tim $\mathrm{J} \mathrm{Cole}^{2}$

${ }^{1}$ Paris 13 University, Nutritional Epidemiology Research Team, French National Institute of Health and Medical Research (Inserm) U1153, French National Institute for Agricultural Research (Inra) U1125, French National Conservatory of Arts and Crafts (CNAM), Sorbonne Paris Cité University, Bobigny, France

${ }^{2}$ UCL Great Ormond Street Institute of Child Health, London, UK

Keywords: adiposity rebound, growth trajectories, BMI, metabolic diseases

Running title: Age at adiposity rebound and critical period

Corresponding author: Professor T J Cole

UCL Great Ormond Street Institute of Child Health

30 Guilford Street

London WC1N 1EH

UK tim.cole@ucl.ac.uk

Conflicts of interest: none

Funding: TJC was funded by Medical Research Council grant MR/M012069/1
Formatted: French (France)

Formatted: Default Paragraph Font, French (France) 


\begin{abstract}
In 1984, Rolland-Cachera et al. showed that the age at adiposity rebound (AR) was associated ${ }^{+}$ with later weight status, whereby an early AR confers greater risk of obesity. This growth pattern is particularly associated with metabolic risk, likely influenced by early environmental factors preceding the AR. In 2004, Cole showed that the age at AR reflects the degree of BMI centile crossing occurring at that time, and he concluded that as a statistical phenomenon it did not constitute a critical period. The question for discussion here is: does the age at AR reflect a critical period? Either way early AR The conclusion is a useful predictor of that it $\underline{\text { does not, and that its value in predicting later obesity and confirmsarises because it reflects }}$ the impact of an earlier critical period. Thus, either way, the AR constitutes an early marker of later risk of obesity and emphasises the importance of early life in determining later health.
\end{abstract} Formatted: Space Before: $6 \mathrm{pt}$, After: $6 \mathrm{pt}$

\title{
Introduction
}

In 1984, based on the observation of body mass index (BMI) trajectories, Rolland-Cachera et

al. first identified the "adiposity rebound" (AR) which corresponds to the second rise in adiposity occurring by). It is the age corresponding to the nadir of 6 yearsthe BMI curve when BMI, after a rise in infancy and subsequent fall, starts to rise again (1). They These authors

Formatted: Font: Not Bold showed that an early rebound was associated with later risk of obesity and pointed out the importance of that the early lifeperiod preceding the rebound appeared to be a critical period determining later health $(1,2)$.

Formatted: Font: Not Bold

Dietz (3) subsequentlydefined a critical period in this context as "a developmental stage in which physiologic alterations increase the later prevalence of obesity", and he suggested that "the time of adiposity rebound may represent a critical period for the development of adiposity", but later". Later he noted that "an earlier rebound of BMI occurs at higher percentiles", and concluded it did not"the period of AR could represent an epiphenomenon" (4). Cole (5) showed that the age at AR statistically reflects the degree of BMI centile crossing occurring at that time, and as such it didthus explaining why AR is predictive. But he also pointed out that a critical period should be bounded with a distinct beginning and end, and since this association applies at any age, the age at AR does not constitute a critical period. _The papers by Dietz and Cole $(3-4,5)$ have since been interpreted by some as Formatted: Space Before: $6 \mathrm{pt}$, After: $6 \mathrm{pt}$ Formatted: Font: Not Bold criticizing the AR concept. 
The aim of this commentary is to emphasise the value of the age at AR, critical period or not. The authors address the issue from their complementary viewpoints, i.e. the association of BMI trajectories with risk factors on the one hand, and a statistical approach on the other.

\section{Observational approach}

Growth curves are useful tools to identify critical periods for child development. In contrast to weight, the BMI-for-age curves showcurve shows ascending and descending phases-which reflect, a pattern that reflects body fat development, e.g. skinfold thickness $(3,6)$ and likely corresponds to variations in the cellularity of adipose tissue (1). Originally the AR was detected on individual BMI curves (1), and an early AR was subsequently shown to predict later overweight independently of BMI level at rebound (1, 6-1011).

\section{From early childhood (before the age of 6 years corresponding to mean age at rebound) until} adulthood, most children change BMI level category $(7,8)$ (Figure S1). Changes in weight status appear clearly on individual BMI curves-(Figure S2). The ages at AR recorded on these curves easily visualize the different types of trajectoriestrajectory and help understand the low BMI tracking from early to late childhood. For example, a fat child will stay fat after an early rebound or join the median after a late rebound, while a thin child can become overweight after an early rebound or stay thin after a late rebound $(\mathbf{2}, 6)$ (Figure S1)- $\underline{8})$.

As a rule, unlike high BMI centiles presenting an early rebound (4), individual BMI trajectories associated with an early AR are characterized by an average or low BMI at or before the rebound, and by an increase in BMI only after the rebound (6-1213) (Figure 1a). This pattern is now recognized to be particularly associated with later metabolic risksdisease $(6,11-12,13)$. One possible underlying mechanism could be alterations in body composition (14). By contrast with obesity starting in early life (15) (Figure 1b), low postnatal BMI gain preceding an early rebound (Figure 1a) mightmay be associated with subsequent lower lean body mass relative to fat mass. Indeed, low BMI gain before the age of 2 years has been shown to reduce adult lean body mass (14), thus increasing metabolic risks such as insulin resistance (14-16).

Finally, the early rebound recorded in most children with obesity constitutes an early marker of later risk of obesity. It reveals the existence of processes initiated during a critical period starting in early life but not specifically atbefore the age of the AR. This suggestion proposed earlier $(1,2)$ was a primary step toward the concept of "early programming" (or "1000

Formatted: Keep with next

Formatted: Space Before: $6 \mathrm{pt}$, After: $6 \mathrm{pt}$

Formatted: Font: Not Bold

Formatted: English (U.S.)

Formatted: Font: Not Bold, English (U.S.)

Formatted: English (U.S.)

Formatted: Font: Not Bold, English (U.S.)

Formatted: English (U.S.)

Formatted: English (U.S.)

Formatted: English (U.S.)

Formatted: English (U.S.)

Formatted: English (U.S.)

Formatted: Font: Not Bold, English (U.S.)

Formatted: English (U.S.)

Formatted: Font: Not Bold, English (U.S.)

Formatted: English (U.S.)

Formatted: Font: Not Bold, English (U.S.)

Formatted: English (U.S.)

Formatted: English (U.S.)

Formatted: Space Before: 6 pt, After: 6 pt

Formatted: English (U.S.)

Formatted: Font: Not Bold, English (U.S.)

Formatted: Font: Not Bold, English (U.S.)

Formatted: English (U.S.)

Formatted: Font: Not Bold, English (U.S.)

Formatted: English (U.S.)

Formatted: Font: Not Bold, English (U.S.)

Formatted: English (U.S.)

Formatted: Font: Not Bold, English (U.S.)

Formatted: English (U.S.)

Formatted: Font: Not Bold, English (U.S.)

Formatted: English (U.S.)

Formatted: English (U.S.)

Formatted: Font: Not Bold, English (U.S.)

Formatted: English (U.S.)

Formatted: Font: Not Bold, English (U.S.)

Formatted: English (U.S.)

Formatted: Font: Not Bold 
days")", i.e. from conception to age 2 years) developed later on (17). During this period preceding the AR, environmental factors may have operated, modifying BMI trajectories, altering body composition and programming later metabolic disease $(2,18)$-diseases. Potential factors driving an early rebound could be maternal BMI, gestational diabetes, formula feeding, high dietary protein intake, or other factors promoting accelerated growth, all of them likely involving epigenetic modifications $(2,3,17,18)$.

\section{Statistical approach}

Cole (5) showed that the age at AR was linked to the underlying pattern of BMI centile change, with a rising trend in centile over time, i.e. upward centile crossing, corresponding to an earlier AR and a falling trend to a later AR. A rising trend in BMI centile at one age statistically predicts a higher BMI centile at later ages, which may explain why the age at AR is predictive. This same association also operates in reverse, so that a child whose BMI centile is on a rising trend is likely to have been on a lower centile before. Thus the age at AR is statistically associated both with a higher centile at AR and an even higher centile later (19). This association should hold quite generally, without the need to invoke any special biological timing. So the existence of the AR does not reflect a critical period- because the period when the association holds is not bounded in time.

Cole's argument (5) compared the child's age at AR to the age at AR on the child's BMI centile curve. But another approach is to compare the child's age at AR to the median age at AR. This ignores the child's BMI centile and focuses instead on the timing of AR. As such it links directly to the concept of developmental age, which is defined by the timing of relevant developmental markers. In this sense the age at AR is just another developmental marker, analogous to other well-established markers such as menarcheal age or bone age (1). The timing of the markerseach marker indicates advanced or delayed developmental age, and advanced developmental age (i.e. an early AR) is known to be a risk factor for later obesity (20). This in turn has well-established implications for metabolic health in later childhood and adulthood. As a marker it occurs relatively early in life - much earlier say than pubertal markers such as menarche - and thus it provides an early glimpse of later developmental risk. The However the child's developmental age is likely to behave been set during a critical period even earlier in early life, eceurringwell before their age at AR, so that the age at AR reflectsis a later manifestation of this critical period but is not itself a critical period (2).
Formatted: Font: Not Bold

Formatted: Keep with next

Formatted: Font: Not Bold

Formatted: Space Before: 6 pt, After: 6 pt

Formatted: Font: Not Bold

Formatted: English (U.S.)

Formatted: Font: Not Bold, English (U.S.)

Formatted: Font: Not Bold

Formatted: Font: Italic

Formatted: Font: Not Bold

Formatted: Font: Not Bold

Formatted: English (U.S.) 


\section{Conclusion}

Whichever way it is interpreted, either visually or statistically, the AR highlights the early developmental processes driving the risk of later obesity. The two approaches confirm the importance of early life as a critical period programming later health risk-a period that predates the age at AR. ResearchThe AR is not itself a critical period, but research on factors responsible for an early AR should help understand the early mechanisms for the development of obesity.

\section{References}

1. Rolland-Cachera MF, Deheeger M, Bellisle F, Sempé M, Guilloud-Bataille M, Patois E. Adiposity rebound in children: a simple indicator for predicting obesity. Am J Clin Nutr 1984;39:129-35.

2. Rolland-Cachera MF, Deheeger M, Maillot M, Bellisle F. Early adiposity rebound: causes and consequences for obesity in children and adults. Int J Obesity 2006;30:S11$\mathrm{S} 17$.

3. Dietz WH. Critical periods in childhood for the development of obesity. Am J Clin Nutr 1994;59:955-9.

4. Dietz WH. “Adiposity rebound": reality or epiphenomenon? Lancet 2000:356:2027-8.

5. Cole TJ. Children grow and horses race: is the adiposity rebound a critical period for later obesity? BMC Pediatr 2004;4:6.

6. Rolland-Cachera MF, Akrout M, Péneau S (2015). History and meaning of the body mass index. Interest of other anthropometric measurements. In M.L. Frelut (Ed.), The ECOG's eBook on Child and Adolescent Obesity. Retrieved from ebook.ecogobesity.eu/chapter-growth-charts-body-composition/history-meaning-body-massindex-interest-anthropometric-measurements/ (Last accessed on February $27^{\text {th }} \underline{\text { June } 14^{\text {th }}}$

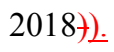

7. Whitaker RC, Pepe MS, Wright JA, Seidel KD, Dietz WH. Early adiposity rebound and the risk of adult obesity. Pediatrics 1998;101:E5.

8. Rolland-Cachera MF, Deheeger M, Guilloud-Bataille M et al. Tracking the development of adiposity from one month of age to adulthood. Ann Hum Biol. 1987;14:219-29.

8.9. Ohlsson C, Lorentzon M, Norjavaara E, Kindblom JM. Age at adiposity rebound is associated with fat mass in young adult males-the GOOD study. PLoS One 2012; 7:e49404. 
9.10. Hughes AR, Sherriff A, Ness AR, Reilly JJ. Timing of adiposity rebound and adiposity in adolescence. Pediatrics 2014;134:e1354-61.

10.11. Williams S, Dickson N. Early growth, menarche, and adiposity rebound. Lancet 2002 Feb 16;359(9306)::580-1.

11.12. Bhargava SK, Sachdev HS, Fall CH et al. Relation of serial changes in childhood body-mass index to impaired glucose tolerance in young adulthood. $\mathrm{N}$ Engl J Med 2004;350:865-875.

12.13. Eriksson JG. Early growth and coronary heart disease and type 2 diabetes: findings from the Helsinki Birth Cohort Study (HBCS). Am J Clin Nutr 2011;94(6 Suppl):1799S-1802S.

13. Rolland-Cachera MF, Cole TJ, Sempé M, Tichet J, Rossignol C, Charraud A. Body mass index variations : centiles from birth to 87 years. Eur J Clin Nutr 1991;45:13-21.

14. Ylihärsilä H, Kajantie E, Osmond C, Forsén T, Barker DJ, Eriksson JG. Body mass index during childhood and adult body composition in men and women aged 56-70 y. Am J Clin Nutr 2008;87:1769-75.

15. Bouhours-Nouet N, Dufresne S, de Casson FB et al. High birth weight and early postnatal weight gain protect obese children and adolescents from truncal adiposity and insulin resistance: metabolically healthy but obese subjects? Diabetes Care 2008;31:1031-6.

16. Giudici KV, Rolland-Cachera MF, Gusto G et al. Body mass index growth trajectories associated with the different parameters of the metabolic syndrome at adulthood. Int $\mathrm{J}$ Obes (Lond) 2017;41:1518-1525.

17. Hanley B, Dijane J, Fewtrell M et al. Metabolic imprinting, programming and epigenetics - a review of present priorities and future opportunities. Br J Nutr. 2010;104 Suppl 1:S1-25.

18. Rolland-Cachera MF, Akrout M, Péneau S. Nutrient intakes in early life and risk of obesity. Int J Environ Res Public Health 2016;13:564. doi: 10.3390/ijerph13060564.

19. Williams SM. Weight and height growth rate and the timing of adiposity rebound. Obesity Research 2005;13:1123-1130.

20. Williams SM, Goulding A. Patterns of growth associated with the timing of adiposity rebound. Obesity 2009;17:335-341. 


\section{Figure legend}

\section{Figure 1.}

BMI trajectories according to age at adiposity rebound (Figure 1aAR) (a) and BMI level at 6 + years (Figure 1b므), plotted against the 3rd and 97th centiles of the French BMI references (13reference (6). Groups are split at the median value of each indicator. The BMI curves Formatted: Space Before: $6 \mathrm{pt}$, After: $6 \mathrm{pt}$ based on either an early age at AR or a high BMI at 6 years both lead to later overweight, but following different trajectories, and are likely not associated with the same health outcomes. (Data from the ELANCE Longitudinal Study (2), 6)).

Formatted: Not Superscript/ Subscript

Formatted: Not Superscript/ Subscript

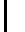




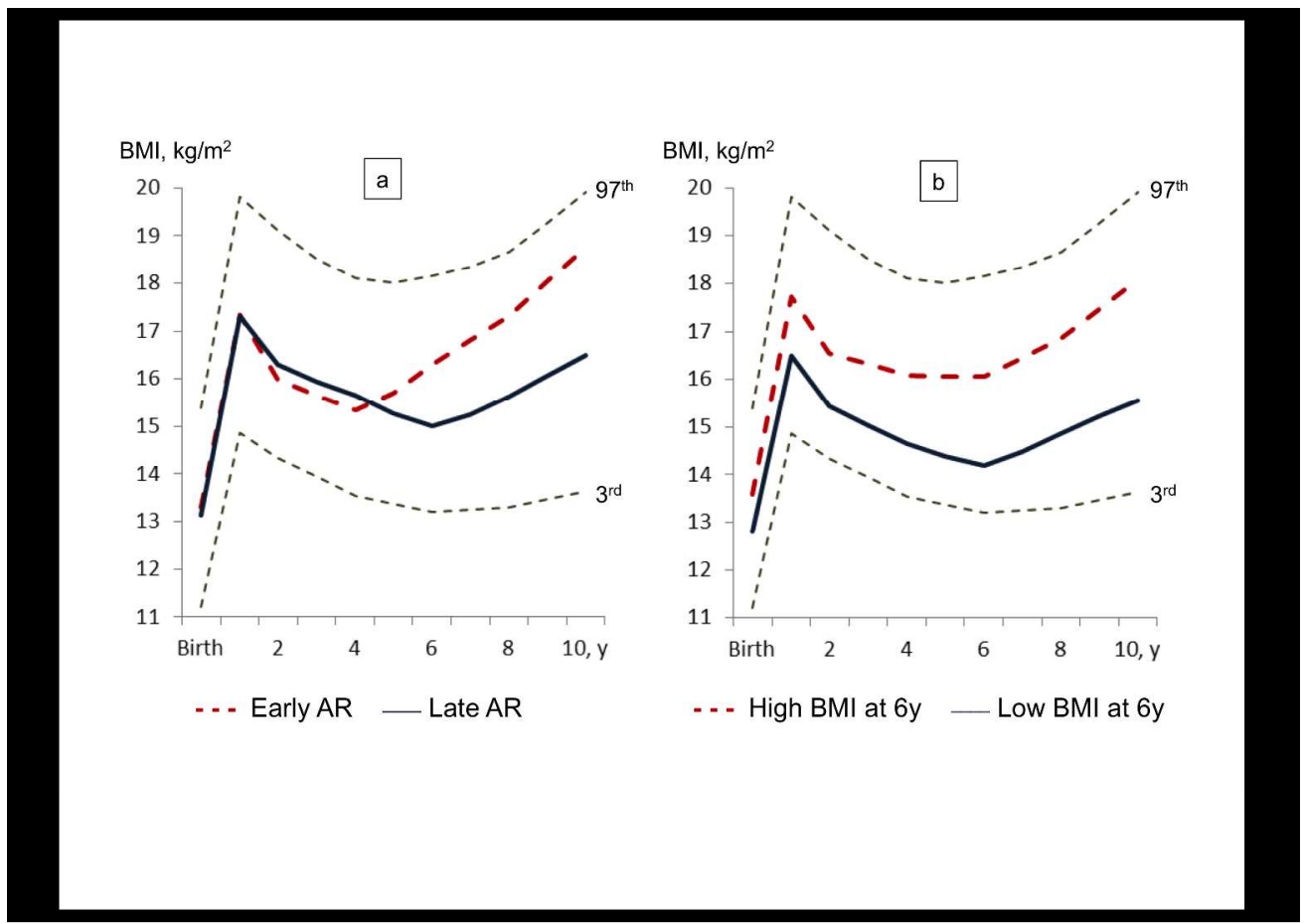

BMI trajectories according to age at adiposity rebound (AR) (a) and BMI level at 6 years (b), plotted against the 3rd and 97th centiles of the French BMI reference (6). Groups are split at the median value of each indicator. The BMI curves based on either an early age at AR or a high BMI at 6 years both lead to later overweight, but following different trajectories, and are likely not associated with the same health outcomes. (Data from the ELANCE Longitudinal Study $(2,6)$ ). 


\section{Does the age at adiposity rebound reflect a critical period?}

Marie Françoise Rolland-Cachera ${ }^{1}$ and Tim J Cole ${ }^{2}$

${ }^{1}$ Paris 13 University, Nutritional Epidemiology Research Team, French National Institute of Health and Medical Research (Inserm) U1153, French National Institute for Agricultural Research (Inra) U1125, French National Conservatory of Arts and Crafts (CNAM), Sorbonne Paris Cité University, Bobigny, France mf.cachera@eren.smbh.univ-paris13.fr

${ }^{2}$ UCL Great Ormond Street Institute of Child Health, London, UK tim.cole@ucl.ac.uk

\section{Figure S1.}
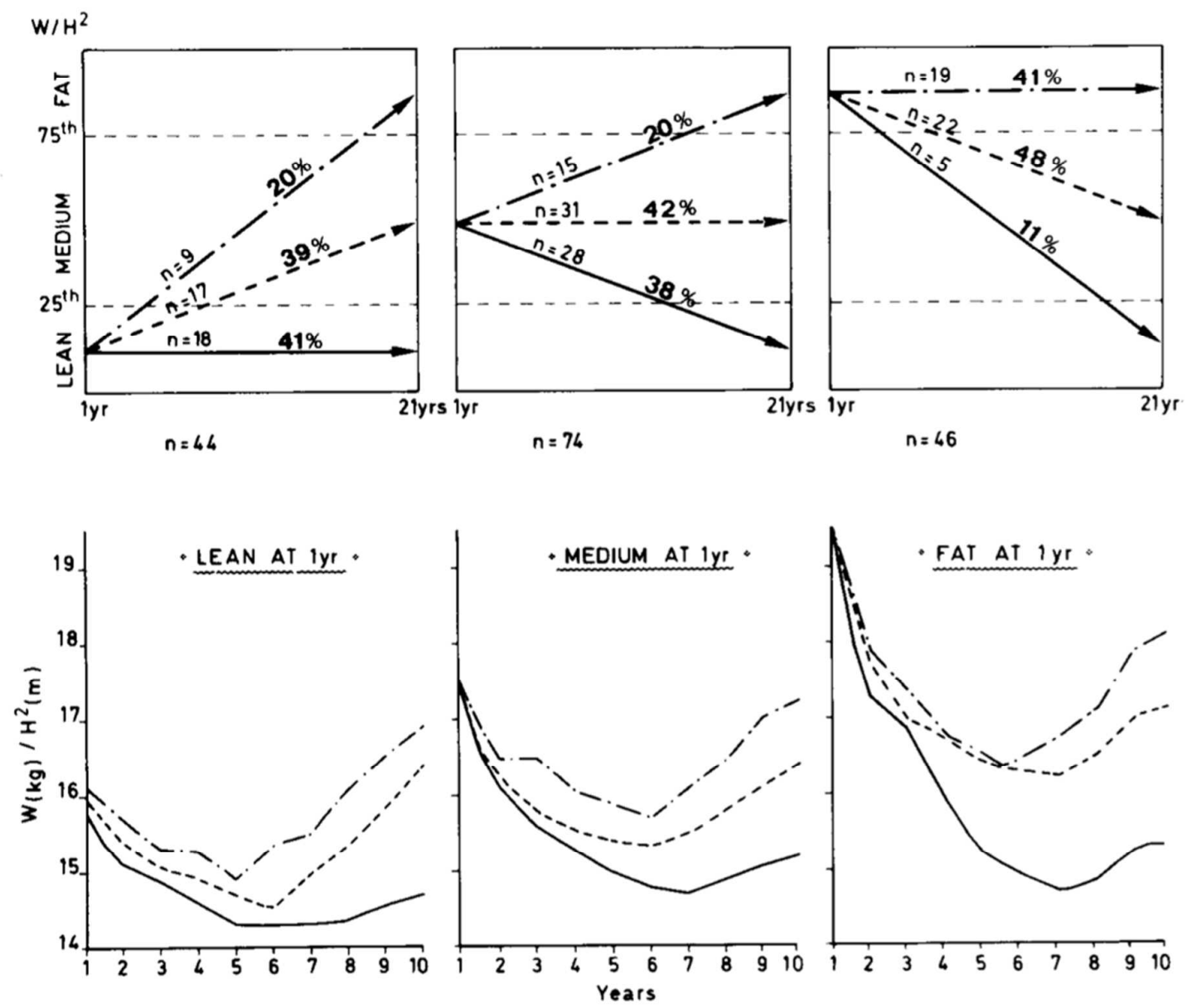

Top: Distribution of BMI development from 1 to 21 years according to BMI categories at 1 and 21 years based on the $25^{\text {th }}$ and $75^{\text {th }}$ centiles of the French reference (6).

Bottom: The corresponding BMI curves of the same groups of subjects between 1 and 10 years (Rolland-Cachera et al. Ann Hum Biol 1987 (8). Reproduced by kind permission of Taylor and Francis http://tandfonline.com). 


\section{Figure S2.}

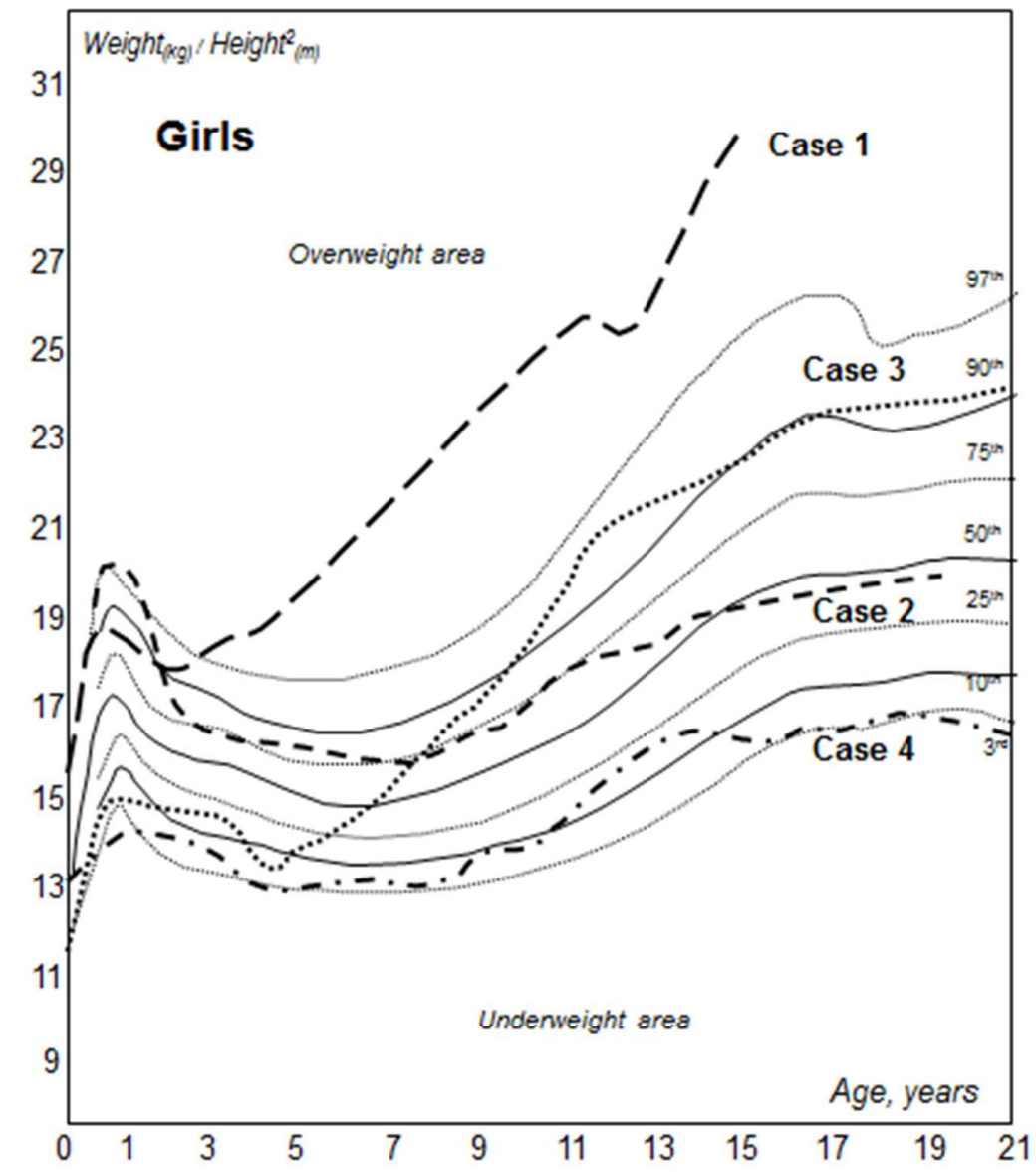

Four examples of Body Mass Index development plotted against the French reference (6):

Case 1, fat at 1 year, remained fat after an early adiposity rebound (2 years);

Case 2, fat at 1 year, did not stay fat after a late rebound ( 8 years);

Case 3 , thin at 1 year, became fatter after an early rebound (4.5 years);

Case 4, thin at 1 year, remained thin after a late rebound ( 8 years).

The four examples are from the French reference study (6).

(Rolland-Cachera et al. Ann Hum Biol 1987 (8)). 


\section{Does the age at adiposity rebound reflect a critical period?}

Marie Françoise Rolland-Cachera ${ }^{1}$ and Tim J Cole ${ }^{2}$

${ }^{1}$ Paris 13 University, Nutritional Epidemiology Research Team, French National Institute of Health and Medical Research (Inserm) U1153, French National Institute for Agricultural Research (Inra) U1125, French National Conservatory of Arts and Crafts (CNAM), Sorbonne Paris Cité University, Bobigny, France

${ }^{2}$ UCL Great Ormond Street Institute of Child Health, London, UK

Keywords: adiposity rebound, growth trajectories, BMI, metabolic diseases

Running title: Age at adiposity rebound and critical period

Corresponding author: Professor T J Cole

UCL Great Ormond Street Institute of Child Health

30 Guilford Street

London WC1N 1EH

UK

$\underline{\text { tim.cole@ucl.ac.uk }}$

Conflicts of interest: none

Funding: TJC was funded by Medical Research Council grant MR/M012069/1 


\begin{abstract}
In 1984, Rolland-Cachera et al. showed that the age at adiposity rebound (AR) was associated with later weight status, whereby an early AR confers greater risk of obesity. This growth pattern is particularly associated with metabolic risk, likely influenced by early environmental factors preceding the AR. In 2004, Cole showed that the age at AR reflects the degree of BMI centile crossing occurring at that time, and he concluded that as a statistical phenomenon it did not constitute a critical period. The question for discussion here is: does the age at AR reflect a critical period? The conclusion is that it does not, and that its value in predicting later obesity arises because it reflects the impact of an earlier critical period. Thus, either way, the AR constitutes an early marker of later risk of obesity and emphasises the importance of early life in determining later health.
\end{abstract}

\title{
Introduction
}

In 1984, based on the observation of body mass index (BMI) trajectories, Rolland-Cachera et al. first identified the "adiposity rebound" (AR). It is the age corresponding to the nadir of the BMI curve when BMI, after a rise in infancy and subsequent fall, starts to rise again (1).

These authors showed that an early rebound was associated with later risk of obesity and pointed out that the period preceding the rebound appeared to be a critical period determining later health $(1,2)$. Dietz (3) defined a critical period in this context as "a developmental stage in which physiologic alterations increase the later prevalence of obesity", and he suggested that "the time of adiposity rebound may represent a critical period for the development of adiposity". Later he noted that "an earlier rebound of BMI occurs at higher percentiles", and concluded "the period of AR could represent an epiphenomenon" (4). Cole (5) showed that the age at AR statistically reflects the degree of BMI centile crossing occurring at that time, thus explaining why AR is predictive. But he also pointed out that a critical period should be bounded with a distinct beginning and end, and since this association applies at any age, the age at AR does not constitute a critical period. The papers by Dietz and Cole $(4,5)$ have since been interpreted by some as criticizing the AR concept.

The aim of this commentary is to emphasise the value of the age at AR, critical period or not. The authors address the issue from their complementary viewpoints, i.e. the association of BMI trajectories with risk factors on the one hand, and a statistical approach on the other. 


\section{Observational approach}

Growth curves are useful tools to identify critical periods for child development. In contrast to weight, the BMI-for-age curve shows ascending and descending phases, a pattern that reflects body fat development, e.g. skinfold thickness $(3,6)$ and likely corresponds to variations in the cellularity of adipose tissue (1). Originally the AR was detected on individual BMI curves (1), and an early AR was subsequently shown to predict later overweight independently of BMI level at rebound (1, 6-11).

From early childhood (before the age of 6 years corresponding to mean age at rebound) until adulthood, most children change BMI level category $(7,8)$ (Figure S1). Changes in weight status appear clearly on individual BMI curves (Figure S2). The ages at AR recorded on these curves easily visualize the different types of trajectory and help understand the low BMI tracking from early to late childhood. For example, a fat child will stay fat after an early rebound or join the median after a late rebound, while a thin child can become overweight after an early rebound or stay thin after a late rebound (8).

As a rule, unlike high BMI centiles presenting an early rebound (4), individual BMI trajectories associated with an early AR are characterized by an average or low BMI at or before the rebound, and by an increase in BMI only after the rebound (6-13) (Figure 1a). This pattern is now recognized to be particularly associated with later metabolic disease $(6,12,13)$. One possible underlying mechanism could be alterations in body composition (14). By contrast with obesity starting in early life (15) (Figure 1b), low postnatal BMI gain preceding an early rebound (Figure 1a) may be associated with subsequent lower lean body mass relative to fat mass. Indeed, low BMI gain before the age of 2 years has been shown to reduce adult lean body mass (14), thus increasing metabolic risks such as insulin resistance (14-16).

Finally, the early rebound recorded in most children with obesity constitutes an early marker of later risk of obesity. It reveals the existence of processes initiated during a critical period starting in early life before the age of the AR. This suggestion proposed earlier $(1,2)$ was a primary step toward the concept of "early programming" (or "1000 days", i.e. from conception to age 2 years) developed later on (17). During this period preceding the AR, environmental factors may have operated, modifying BMI trajectories, altering body composition and programming later metabolic diseases. Potential factors driving an early rebound could be maternal BMI, gestational diabetes, formula feeding, high dietary protein intake, or other factors promoting accelerated growth, all of them likely involving epigenetic modifications $(2,3,17,18)$. 


\section{Statistical approach}

Cole (5) showed that the age at AR was linked to the underlying pattern of BMI centile change, with a rising trend in centile over time, i.e. upward centile crossing, corresponding to an earlier AR and a falling trend to a later AR. A rising trend in BMI centile at one age statistically predicts a higher BMI centile at later ages, which may explain why the age at AR is predictive. This same association also operates in reverse, so that a child whose BMI centile is on a rising trend is likely to have been on a lower centile before. Thus the age at AR is statistically associated both with a higher centile at AR and an even higher centile later (19). This association should hold quite generally, without the need to invoke any special biological timing. So the existence of the AR does not reflect a critical period because the period when the association holds is not bounded in time.

Cole's argument (5) compared the child's age at AR to the age at AR on the child's BMI centile curve. But another approach is to compare the child's age at AR to the median age at AR. This ignores the child's BMI centile and focuses instead on the timing of AR. As such it links directly to the concept of developmental age, which is defined by the timing of relevant developmental markers. In this sense the age at AR is just another developmental marker, analogous to other well-established markers such as menarcheal age or bone age (1). The timing of each marker indicates advanced or delayed developmental age, and advanced developmental age (i.e. an early AR) is known to be a risk factor for later obesity (20). This in turn has well-established implications for metabolic health in later childhood and adulthood. As a marker it occurs relatively early in life - much earlier say than pubertal markers such as menarche - and thus it provides an early glimpse of later developmental risk. However the child's developmental age is likely to have been set during a critical period even earlier in life, well before their age at AR, so that the age at $\mathrm{AR}$ is a later manifestation of this critical period but is not itself a critical period (2).

\section{Conclusion}

Whichever way it is interpreted, either visually or statistically, the AR highlights the early developmental processes driving the risk of later obesity. The two approaches confirm the importance of early life as a critical period programming later health risk-a period that predates the age at AR. The AR is not itself a critical period, but research on factors responsible for an early AR should help understand the early mechanisms for the development of obesity. 


\section{References}

1. Rolland-Cachera MF, Deheeger M, Bellisle F, Sempé M, Guilloud-Bataille M, Patois E. Adiposity rebound in children: a simple indicator for predicting obesity. Am J Clin Nutr 1984;39:129-35.

2. Rolland-Cachera MF, Deheeger M, Maillot M, Bellisle F. Early adiposity rebound: causes and consequences for obesity in children and adults. Int J Obesity 2006;30:S11S17.

3. Dietz WH. Critical periods in childhood for the development of obesity. Am J Clin Nutr 1994;59:955-9.

4. Dietz WH. “Adiposity rebound”: reality or epiphenomenon? Lancet 2000:356:2027-8.

5. Cole TJ. Children grow and horses race: is the adiposity rebound a critical period for later obesity? BMC Pediatr 2004;4:6.

6. Rolland-Cachera MF, Akrout M, Péneau S (2015). History and meaning of the body mass index. Interest of other anthropometric measurements. In M.L. Frelut (Ed.), The ECOG's eBook on Child and Adolescent Obesity. Retrieved from ebook.ecogobesity.eu/chapter-growth-charts-body-composition/history-meaning-body-massindex-interest-anthropometric-measurements/ (Last accessed on June $14^{\text {th }} 2018$ ).

7. Whitaker RC, Pepe MS, Wright JA, Seidel KD, Dietz WH. Early adiposity rebound and the risk of adult obesity. Pediatrics 1998;101:E5.

8. Rolland-Cachera MF, Deheeger M, Guilloud-Bataille M et al. Tracking the development of adiposity from one month of age to adulthood. Ann Hum Biol. 1987;14:219-29.

9. Ohlsson C, Lorentzon M, Norjavaara E, Kindblom JM. Age at adiposity rebound is associated with fat mass in young adult males-the GOOD study. PLoS One 2012;7:e49404.

10. Hughes AR, Sherriff A, Ness AR, Reilly JJ. Timing of adiposity rebound and adiposity in adolescence. Pediatrics 2014;134:e1354-61.

11. Williams S, Dickson N. Early growth, menarche, and adiposity rebound. Lancet 2002 Feb 16;359:580-1.

12. Bhargava SK, Sachdev HS, Fall CH et al. Relation of serial changes in childhood body-mass index to impaired glucose tolerance in young adulthood. N Engl J Med 2004;350:865-875. 
13. Eriksson JG. Early growth and coronary heart disease and type 2 diabetes: findings from the Helsinki Birth Cohort Study (HBCS). Am J Clin Nutr 2011;94(6 Suppl):1799S-1802S.

14. Ylihärsilä H, Kajantie E, Osmond C, Forsén T, Barker DJ, Eriksson JG. Body mass index during childhood and adult body composition in men and women aged 56-70 y. Am J Clin Nutr 2008;87:1769-75.

15. Bouhours-Nouet N, Dufresne S, de Casson FB et al. High birth weight and early postnatal weight gain protect obese children and adolescents from truncal adiposity and insulin resistance: metabolically healthy but obese subjects? Diabetes Care 2008;31:1031-6.

16. Giudici KV, Rolland-Cachera MF, Gusto G et al. Body mass index growth trajectories associated with the different parameters of the metabolic syndrome at adulthood. Int $\mathbf{J}$ Obes (Lond) 2017;41:1518-1525.

17. Hanley B, Dijane J, Fewtrell M et al. Metabolic imprinting, programming and epigenetics - a review of present priorities and future opportunities. Br J Nutr. 2010;104 Suppl 1:S1-25.

18. Rolland-Cachera MF, Akrout M, Péneau S. Nutrient intakes in early life and risk of obesity. Int J Environ Res Public Health 2016;13:564. doi: 10.3390/ijerph13060564.

19. Williams SM. Weight and height growth rate and the timing of adiposity rebound. Obesity Research 2005;13:1123-1130.

20. Williams SM, Goulding A. Patterns of growth associated with the timing of adiposity rebound. Obesity 2009;17:335-341. 


\section{Figure legend}

\section{Figure 1.}

BMI trajectories according to age at adiposity rebound (AR) (a) and BMI level at 6 years (b), plotted against the 3rd and 97th centiles of the French BMI reference (6). Groups are split at the median value of each indicator. The BMI curves based on either an early age at AR or a high BMI at 6 years both lead to later overweight, but following different trajectories, and are likely not associated with the same health outcomes. (Data from the ELANCE Longitudinal Study $(2,6))$. 